\title{
Perbandingan Efektivitas Z Spring dengan Coil dan Z Spring tanpa Coil terhadap Koreksi Malposisi Gigi Individual
}

\author{
Angel E. Pusung, Pritartha S. Anindita, Aurelia S. R. Supit
}

\author{
Program Studi Pendidikan Dokter Gigi Fakultas Kedokteran Universitas Sam Ratulangi \\ Manado, Indonesia
}

Email: angelpusung15@gmail.com

Disubmisi: 23 Juli 2021; direvisi: 4 Agustus 2021; diterima: 8 Agustus 2021

\begin{abstract}
Malocclusion problem is often found in the community. $Z$ spring, one of the springs of the active component of removable orthodontic appliances, is divided into two types, namely $\mathrm{Z}$ spring with coil and without coil. Both can move teeth in a labial direction, therefore, they can be used to correct simple cases of malocclusion such as malposition of individual tooth. The addition of coil can increase the resilience and effective length of the spring which further increases the force, hence the malposition of the tooth can be corrected more quickly. This study was aimed to analyze the differences between the effectiveness of $Z$ spring with coil and of $Z$ spring without coil in correction of individual tooth malposition. This was a pre-experimental study with a oneshot case study method. There were two treatment groups, namely $\mathrm{Z}$ spring with coil and without coil. Each sample was activated by $1 \mathrm{~mm}$ per activation to correct tooth with $5 \mathrm{~mm}$ linguoversion in typodonts. After that, the number of activations required and the average value of the measurements of both groups were compared. The independent sample T-Test test on the average value of the displacement distance of each tooth showed that there was a significant difference in effectiveness between the $\mathrm{Z}$ spring with coil and the $\mathrm{Z}$ spring without coil groups ( $\mathrm{p}=0.000$; $\mathrm{p}<0.05$ ). The Mann Whitney test showed that there was also a significant difference in the value of the number of activations for each $Z$ spring sample between the two groups $(p=0.000 ; p<0.05)$. In conclusion, $\mathrm{Z}$ spring with coil is more effective in correction of malposition of individual tooth than $\mathrm{Z}$ spring without coil.
\end{abstract}

Keywords: removable orthodontic appliance; $\mathrm{Z}$ spring with coil; $\mathrm{Z}$ spring without coil

\begin{abstract}
Abstrak: Maloklusi merupakan permasalahan kesehatan gigi dan mulut yang banyak dijumpai dalam masyarakat. $Z$ spring merupakan salah satu pegas dari komponen aktif alat ortodontik lepasan yang terbagi menjadi dua, yakni $Z$ spring dengan coil dan $Z$ spring tanpa coil. Keduanya dapat memindahkan gigi ke arah labial sehingga dapat digunakan untuk mengoreksi kasus maloklusi sederhana seperti malposisi gigi individual. Penambahan coil dapat meningkatkan kelentingan dan panjang efektif spring yang meningkatkan gaya sehingga malposisi gigi dapat terkoreksi lebih cepat. Penelitian ini bertujuan untuk menganalisis perbedaan efektivitas $Z$ spring dengan coil dan tanpa coil dalam mengoreksi malposisi gigi individual. Jenis penelitian ini preexperimental dengan metode one-shot case study. Terdapat dua kelompok perlakuan, yakni $Z$ spring dengan coil dan tanpa coil. Masing-masing sampel penelitian diaktivasi sebesar $1 \mathrm{~mm}$ per aktivasi untuk mengoreksi gigi dengan linguoversi $5 \mathrm{~mm}$ pada typodont kemudian dibandingkan jumlah aktivasi yang dibutuhkan dan nilai rerata perpindahan gigi kedua kelompok. Hasil uji independent sample t-test pada nilai rerata jarak perpindahan masing-masing gigi menunjukkan terdapat perbedaan efektivitas yang bermakna antara kelompok $\mathrm{Z}$ spring dengan coil dan tanpa coil $(\mathrm{p}=0,000 ; \mathrm{p}<0,05)$. Hasil uji Mann Whitney terhadap nilai jumlah aktivasi tiap sampel menunjukkan terdapat perbedaan bermakna pula antara kedua kelompok penelitian $(\mathrm{p}=0,000$; $\mathrm{p}<0,05$ ). Simpulan penelitian ini ialah $Z$ spring dengan coil lebih efektif dalam mengoreksi malposisi gigi individual dibandingkan $Z$ spring tanpa coil.
\end{abstract}

Kata kunci: alat ortodontik lepasan; $Z$ spring dengan coil; $Z$ spring tanpa coil 


\section{PENDAHULUAN}

Kelainan pada susunan gigi-geligi atau maloklusi merupakan salah satu dari berbagai permasalahan kesehatan gigi dan mulut yang banyak dijumpai dalam masyarakat. Data RISKESDAS tahun 2018 menyebutkan bahwa sebanyak $57,6 \%$ masyarakat Indonesia memiliki permasalahan kesehatan gigi dan mulut dan yang mendapatkan pelayanan dari tenaga medis hanya sebanyak $10,2 \% .^{1,2}$

Maloklusi merupakan suatu penyimpangan berupa ketidakharmonitas hubungan antara rahang atas dan rahang bawah dengan penyebab multifaktorial seperti faktor herediter, faktor lingkungan, kelainan bawaan, kebiasaan buruk, trauma, penyakit metabolik, malnutrisi, maupun gabungan dari beberapa faktor tersebut. ${ }^{2-4}$ Perawatan ortodontik dibutuhkan untuk mengoreksi maloklusi yang dapat dibagi menjadi dua, yakni perawatan dengan alat ortodontik lepasan (removable appliances) dan perawatan dengan alat ortodontik cekat (fixed appliances). Alat ortodontik lepasan digunakan untuk mengatasi kasus maloklusi sederhana yang hanya melibatkan kelainan pada posisi gigi, sedangkan alat ortodontik cekat digunakan untuk mengatasi kasus maloklusi berat. ${ }^{3,5,6}$ Salah satu bentuk dari maloklusi gigi sederhana yang dapat dikoreksi dengan alat ortodontik lepasan yakni malposisi gigi individual yaitu suatu kelainan dimana terdapat kesalahan posisi gigi pada lengkung rahang. 3,7

$Z$ spring merupakan salah satu pegas dari komponen aktif alat ortodontik lepasan yang terdiri atas $Z$ spring dengan coil dan $Z$ spring tanpa coil. ${ }^{5,8,9}$ Kedua jenis $Z$ spring ini dapat digunakan untuk memindahkan gigi ke arah labial sehingga cocok untuk mengoreksi malposisi gigi individual. ${ }^{3,10}$ Adanya penambahan coil pada $Z$ spring dapat meningkatkan kelentingan spring dan panjang efektif spring. Selanjutnya, peningkatan daya lenting dan panjang efektif $Z$ spring akan meningkatkan gaya sehingga malposisi gigi individual dapat dikoreksi dengan lebih cepat. ${ }^{5,11}$

Alat ortodontik lepasan dengan $Z$ spring dapat membantu mengatasi perma- salahan maloklusi sederhana. Sampai saat ini belum terdapat penelitian lebih lanjut mengenai perbandingan efektivitas komponen alat ortodontik lepasan, khususnya $Z$ spring dengan dan tanpa coil. Hal ini yang mendorong penulis untuk mengetahui lebih lanjut perbedaan efektivitas $Z$ spring dengan coil dan tanpa coil dalam mengoreksi malposisi gigi individual. Mengingat kondisi pandemi COVID-19 saat ini yang tidak memungkinkan untuk melakukan penelitian langsung terhadap pasien maka penulis menggunakan alternatif lain yaitu dengan menggunakan model rahang tiruan berbasis malam merah (typodont).

\section{METODE PENELITIAN}

Penelitian ini bertujuan untuk mengetahui dan menganalisis perbandingan efektivitas $Z$ spring dengan coil dan $\mathrm{Z}$ Spring tanpa coil dalam mengoreksi malposisi gigi individual pada typodont. Penelitian dilakukan pada bulan Juni 2021 di Ruang Skill Lab Program Studi Pendidikan Dokter Gigi (PSPDG) Fakultas Kedokteran Univer-sitas Sam Ratulangi (Unsrat) Manado. Metode penelitian yang digunakan ialah preexperimental dengan rancangan one-shot case study. Pada penelitian ini digunakan total sampling yang terdiri dari dua kelompok perlakuan yakni, $Z$ spring dengan coil dan $Z$ spring tanpa coil. Besaran sampel penelitian ditentukan dengan menggunakan rumus Federer.

Penelitian ini diawali dengan pembagian dan penandaan sampel menjadi dua kelompok. Kelompok 1 yaitu $Z$ spring dengan coil ditandai dengan model 1-8 dan kelompok 2 yaitu $Z$ spring tanpa coil ditandai dengan model I-VIII dan dilanjutkan dengan perendaman seluruh model typodont agar malam merah typodont melunak sehingga gigi 32 dan 42 dapat dimodifikasi menjadi linguoversi $5 \mathrm{~mm}$. Kemudian seluruh model typodont dicetak menggunakan alginat dan dicor dengan gips biru. Setelah itu seluruh model gips biru dikirimkan ke laboratorium untuk dibuatkan alat ortodontik lepasannya.

Setelah seluruh alat ortodontik lepasan selesai dibuat, kemudian dipasangkan pada 
setiap model typodont agar tidak tertukar atau hilang. Penelitian dimulai dengan mengaktifkan kedua lengan pada masingmasing model 1 dan model I sebesar $1 \mathrm{~mm}$. Kedua typodont direndam selama 2 menit sampai malam merahnya melunak dan berwarna pucat. Setelah itu, diukur perpindahan gigi kedua model typodont dan dituliskan pada tabel hasil penelitian. Dilakukan beberapa kali aktivasi sampai gigi 32 dan 42 kedua model typodont menyentuh labial bow atau berada pada lengkung rahang yang ideal. Pengukuran selalu dilakukan setiap selesai aktivasi dan perendaman.

Selanjutnya, dilakukan prosedur yang sama untuk model 2-8 dan model II-VIII. Untuk mengukur perbedaan efektivitas kedua jenis $Z$ spring, data nilai rerata perpindahan gigi kedua kelompok dan jumlah aktivasi yang dibutuhkan dibandingkan, diolah, dan dianalisis sehingga dapat diketahui apakah terdapat perbedaan efektivitas atau tidak antara kelompok $Z$ spring dengan coil dan $Z$ spring tanpa coil. Kelompok yang dapat memindahkan gigi lebih cepat dengan jumlah aktivasi yang lebih sedikit dikatakan lebih efektif dalam mengoreksi malposisi gigi individual.

\section{HASIL PENELITIAN}

Berdasarkan penelitian yang telah dilakukan diperoleh nilai rerata perpindahan gigi tiap sampel $\mathrm{Z}$ Spring dan jumlah aktivasi yang dibutuhkan. Tabel 1 dan Tabel 2 memperlihatkan hasil analisis deskriptif nilai rerata jarak perpindahan gigi dan jumlah aktivasi meliputi nilai minimum, maksimum, dan mean dari variabel penelitian.

Tabel 1 memperlihatkan nilai rerata jarak perpindahan gigi. Pada kelompok $Z$ spring dengan coil diperoleh nilai perpindahan terendah $0,66 \mathrm{~mm}$ dan perpindahan tertinggi 0,89 $\mathrm{mm}$, dengan rerata keseluruhan perpindahan gigi kelompok Z Spring dengan coil sebesar 0,7869 mm. Pada kelompok $Z$ spring tanpa coil diperoleh nilai perpindahan terendah $0,55 \mathrm{~mm}$ dan nilai perpindahan tertinggi $0,67 \mathrm{~mm}$, dengan rerata perpindahan gigi keseluruhan kelompok $Z$ spring tanpa coil sebesar $0,6169 \mathrm{~mm}$.

Tabel 2 memperlihatkan nilai jumlah aktivasi tiap sampel. Aktivasi paling sedikit pada kelompok $Z$ spring dengan coil yaitu 4 aktivasi dan aktivasi paling banyak yaitu 6 aktivasi, dan rerata keseluruhan jumlah aktivasi kelompok $Z$ spring dengan coil sebesar 4,88. Pada kelompok $Z$ spring tanpa coil didapatkan bahwa aktivasi paling sedikit yaitu 5 aktivasi dan aktivasi paling banyak yaitu 7 aktivasi, dan rerata keseluruhan jumlah aktivasi kelompok $Z$ spring tanpa coil sebesar 6,13.

Hasil uji normalitas Shapiro-Wilk untuk nilai rerata jarak perpindahan gigi memperoleh nilai $\mathrm{p}=0,053$ untuk kelompok $Z$ spring dengan coil dan $\mathrm{p}=0,295$ untuk kelompok $Z$ spring tanpa coil. Hasil tersebut menunjukkan bahwa data terdistribusi normal karena nilai $\mathrm{p}>0,05$.

Tabel 1. Analisis deskriptif nilai rerata jarak perpindahan gigi

\begin{tabular}{lcccc}
\hline \multicolumn{1}{c}{ Kelompok $\boldsymbol{Z}$ spring } & N & Minimum & Maximum & Mean \\
\hline Dengan coil & 16 & 0,66 & 0,89 & 0,7869 \\
Tanpa coil & 16 & 0,55 & 0,67 & 0,6169 \\
Valid N (listwise) & 16 & & & \\
\hline
\end{tabular}

Tabel 2. Analisis deskriptif jumlah aktivasi

\begin{tabular}{lcccc}
\hline $\begin{array}{l}\text { Jumlah aktivasi kelompok } \\
\text { Z spring }\end{array}$ & N & Minimum & Maximum & Mean \\
\hline Dengan coil & 16 & 4 & 6 & 4,88 \\
Tanpa coil & 16 & 5 & 7 & 6,13 \\
Valid N (listwise) & 16 & & & \\
\hline
\end{tabular}


Jumlah aktivasi memperoleh nilai $\mathrm{p}=0,000$ untuk kelompok $Z$ spring dengan coil dan $\mathrm{p}=0,003$ untuk kelompok $Z$ spring tanpa coil $(\mathrm{p}<0,05)$, sehingga disimpulkan bahwa data tidak berdistribusi normal. Uji homogenitas Levene mendapatkan nilai $\mathrm{p}=0,286$ untuk nilai rerata jarak perpindahan gigi yang berarti data tersebut memiliki varian yang homogen $(\mathrm{p}>0,05)$. Nilai $\mathrm{p}$ pada jumlah aktivasi tiap sampel $Z$ spring sebesar 0,029 yang berarti data tersebut memiliki varian yang tidak homogen $(\mathrm{p}<0,05)$.

Perbedaan efektivitas kedua jenis $Z$ spring dianalisis dengan cara membandingkan nilai rerata jarak perpindahan gigi dan jumlah aktivasi sampel $Z$ spring tiap kelompok. Analisis data tersebut dilakukan dengan menggunakan uji independent sample t-test untuk nilai rerata jarak perpindahan gigi karena datanya terdistribusi normal dan homogen, sedangkan uji MannWhitney untuk jumlah aktivasi tiap kelompok karena datanya tidak terdistribusi normal dan tidak homogen.

Tabel 3 memperlihatkan hasil analisis data tersebut dengan nilai $\mathrm{p}$ dari nilai rerata jarak perpindahan gigi dan jumlah aktivasi sampel $Z$ spring tiap kelompok, keduanya sebesar $0,000(\mathrm{p}<0,05)$ sehingga dapat dikatakan bahwa terdapat perbedaan bermakna pada nilai rerata jarak perpindahan gigi dan jumlah aktivasi kelompok $Z$ spring dengan coil dan kelompok $Z$ spring tanpa coil.

Tabel 3. Analisis perbandingan efektivitas $Z$ spring dengan coil dan tanpa coil dalam mengoreksi malposisi gigi individual

\begin{tabular}{lc}
\hline \multicolumn{1}{c}{ Variabel } & Nilai p \\
\hline $\begin{array}{l}\text { Nilai rerata jarak } \\
\text { perpindahan gigi }\end{array}$ & 0,000 \\
$\begin{array}{l}\text { Jumlah aktivasi sampel } Z \\
\text { spring tiap kelompok }\end{array}$ & 0,000 \\
\hline
\end{tabular}

\section{BAHASAN}

Hasil penelitian ini menunjukkan bahwa terdapat perbedaan efektivitas secara statistik antar kelompok $Z$ spring dengan coil dan $Z$ spring tanpa coil. Hal ini dibuktikan dengan nilai $\mathrm{p}$ uji independent sample t-test pada nilai rerata jarak perpindahan gigi sebesar $0,000(\mathrm{p}<0,05)$ yang menunjukkan adanya perbedaan bermakna. Selain itu, nilai $\mathrm{p}$ uji Mann-Whitney pada data jumlah aktivasi sebesar $0,000(p<0,05)$ yang berarti terdapat perbedaan efektivitas bermakna antara kelompok $Z$ spring dengan coil dan tanpa coil.

Berdasarkan analisis hasil penelitian, didapatkan bahwa nilai rerata keseluruhan jarak perpindahan gigi kelompok $Z$ spring dengan coil sebesar $0,7869 \mathrm{~mm}$ lebih tinggi dibandingkan dengan kelompok $Z$ spring tanpa coil yang hanya sebesar $0,6169 \mathrm{~mm}$. Selain itu, nilai rerata keseluruhan jumlah aktivasi kelompok $Z$ spring dengan coil sebesar 4,88 lebih sedikit dibandingkan kelompok $Z$ spring tanpa coil yakni sebesar 6,13 . Hal ini menunjukkan bahwa kelompok $Z$ spring dengan coil memiliki rerata perpindahan gigi yang lebih besar dengan jumlah aktivasi yang lebih sedikit dibandingkan kelompok $Z$ spring tanpa coil sehingga dapat dikatakan bahwa kelompok $Z$ spring dengan coil lebih efektif dalam mengoreksi malposisi gigi individual.

Penambahan coil akan meningkatkan panjang efektif spring dan meningkatkan kelentingan. ${ }^{3}$ Daya lenting adalah kemampuan kawat untuk dapat kembali ke posisi semula atau beradaptasi dengan perubahan setelah digerakkan ke arah tertentu. Dalam perawatan ortodontik kelentingan sangat diperlukan karena memberikan gaya setelah dilakukan aktivasi sehingga kawat dapat mendorong gigi kearah yang ditentukan. ${ }^{12}$ Defleksi merupakan seberapa jauh spring bergerak dari letak yang semula. Peningkatan daya lenting dan panjang efektif spring akan memperbesar gaya yang dihasilkan sehingga defleksinya akan semakin besar. Dengan kata lain $Z$ spring dapat mendorong gigi lebih jauh, ${ }^{11}$ sehingga $Z$ spring dengan coil akan lebih cepat dalam mengoreksi malposisi gigi individual dibandingkan dengan yang tanpa coil; hal ini sesuai dengan hasil penelitian yang didapatkan.

Idealnya kekuatan yang dihasilkan oleh spring adalah kekuatan yang terus-menerus (continuous force) agar dapat menggerakkan gigi secara terus-menerus pula sampai ke posisi yang diinginkan. Namun, hal ini tidak memungkinkan karena gaya yang dihasilkan oleh spring berbanding lurus 
dengan defleksinya. ${ }^{11,12}$ Jadi, apabila gigi bergerak atau dilakukan defleksi, maka kekuatan spring juga akan berkurang terus sampai habis. Defleksi yang terlalu kecil memberikan gaya dorong yang sedikit dan akan cepat habis sehingga harus sering diaktivasi ataupun menghasilkan pergerakan gigi yang tidak efektif. Dengan adanya penambahan coil maka akan meningkatkan defleksi, sehingga gaya dorong $Z$ spring menjadi lebih besar. Gaya yang besar akan lebih lama habis dan diharapkan akan terjadi pergerakan gigi seperti pada pemberian kekuatan secara terus-menerus. ${ }^{11} \mathrm{Z}$ spring dengan coil terbukti memiliki gaya dorong yang lebih besar. Hal ini dibuktikan dengan melihat perbandingan nilai rerata perpindahan gigi yang menunjukkan bahwa kelompok $Z$ spring dengan coil memiliki nilai yang lebih besar dibandingkan kelompok tanpa coil. Gaya dorong yang dihasilkan $Z$ spring dengan coil menjadi lebih besar dan mengakibatkan gaya tersebut tidak cepat habis dan tidak perlu sering diaktivasi.

Untuk mendapatkan kekuatan daya lenting yang efektif, tidak terlalu besar dan tidak terlalu kecil dalam menggerakkan gigi serta mencapai fleksibilitas maksimum maka dapat dilakukan pemanjangan spring. Karena dimensi rongga mulut terbatas, pemanjangan spring dapat dilakukan dengan penambahan coil. $^{7} \mathrm{Z}$ spring dengan coil akan meningkatkan fleksibilitas dan memberikan gaya dorong lebih besar daripada yang tidak ditambahkan coil. ${ }^{11}$ Dengan demikian dapat disimpulkan bahwa penambahan coil akan meningkatkan kelentingan spring sehingga gaya yang dihasilkan menjadi lebih besar dan malposisi gigi individual akan lebih cepat terkoreksi. Penambahan coil juga meningkatkan panjang efektif $Z$ spring sehingga menjadi lebih fleksibel dan mudah untuk diaktivasi.

\section{SIMPULAN}

$\mathrm{Z}$ Spring dengan coil lebih efektif dibandingkan dengan $\mathrm{Z}$ Spring tanpa coil dalam mengoreksi malposisi gigi individual. Disarankan untuk penelitian lanjut yang lebih memperhatikan faktor yang mungkin memengaruhi hasil penelitian seperti suhu air saat perendaman, atau penelitian yang dilakukan secara langsung pada pasien.

\section{Konflik Kepentingan}

Penulis menyatakan tidak terdapat konflik kepentingan pada studi ini

\section{DAFTAR PUSTAKA}

1.Badan Penelitian dan Pengembangan Kesehat-an. Hasil utama Riset Kesehatan Dasar 2018. Jakarta: Kemenkes RI, 2018; p. 93-6.

2.Wagiran DIL, Kaunang WPJ, Wowor VNS. Kualitas hidup remaja SMA Negeri 6 Manado yang mengalami maloklusi. Jurnal Kedokteran Komunitas dan Tropik. 2014;II(2):85-9.

3.Premkumar S. Textbook of Orthodontics (1st ed). India: Elsevier, 2015; p. 145-6, 17590, 480-1.

4.Proffit WR, Fields HW, Larson BE, Sarver DM. Contemporary Orthodontics (6th ed). St. Louis: Elsevier/Mosby, 2018; p. 1-11, 247-58.

5.Cobourne M, DiBiase A. Handbook of Orthodontics (2nd ed). Edinburgh: Mosby Elsevier, 2016; p. 1-16.

6.Mitchell L, Littlewood SJ, Nelson-Moon ZL, Dyer F. An introduction to Orthodontics (4th ed). Oxford, UK: Oxford University Press, 2013; p. 10-5.

7.Isaacson KG, Muir JD, Reed RT. Removable Orthodontic Appliances. New Delhi, India: Elsevier, 2006; p. 15-28.

8.Phulari BS. Orthodontics: Principles and Practice (2nd ed). New Delhi: Jaypee Brothers Medical Publishers, 2017; p. 297-315.

9.Luther F, Nelson-Moon Z. Orthodontic Retainers and Removable Appliances: Principles of Design and Use. Chichester: WileyBlackwell, 2013; p. 28-30, 48-50.

10.Rahardjo P. Ortodonti Dasar (2th ed). Surabaya: Airlangga University Press, 2019; p. 69-79.

11.Rahardjo P. Peranti Ortodonti Lepasan. Surabaya: Airlangga University Press, 2009; p. 2-15.

12.Peniasi. Efek perendaman minuman probiotik terhadap daya lenting kawat ortodontik lepasan stainless steel. Dentin J Kedokteran Gigi. 2018;II(1):103-7. 